\title{
Functional Importance of Laparoscopic Sleeve Gastrectomy for the Lower Esophageal Sphincter in Patients with Morbid Obesity
}

\author{
Wiebke Veronika Petersen • Joachim Helmut Schneider
}

Published online: 3 April 2012

(C) Springer Science+Business Media, LLC 2012

Keywords LSG · LESP. Morbid obesity · Reflux

Dear Deana Rodriguez,

Reply to the comment to the paper: Functional importance of laparoscopic sleeve gastrectomy for the lower esophageal sphincter in patients with morbid obesity.

Many thanks for giving us the opportunity to reply to the comment of Dr. Raj. We agree to the arguments which are described by the commentator to our paper, but we do not see any contradiction to the content of the paper. Also, in our series, we found patients with a weak lower esophageal sphincter pressure (LESP) after laparoscopic sleeve gastrectomy (LSG). We compared those patients with patients in whom sphincter pressure was doubled after operation. We were indeed surprised to find a significant difference in the surgical strategy as we prescribed in the paper. Dr. Raj is quite correct when he emphasizes that the LESP is not the only factor to prevent a patient's esophagus from gastric juice reflux, but most investigators agree that the LES is the major determinant to prevent gastro-esophageal reflux. So what can we offer to those obese patients, in whom reflux was detected before operation? Certainly, this is not even much. The paper delivered data for a surgical option to influence the occurrence of reflux postoperatively. However, this is in fact one option, and in the future, we are convinced to find more solutions to avoid this complication after LSG.

Yours sincerely,

WV Petersen

Conflict of Interest None.
W. V. Petersen · J. H. Schneider $(\bowtie)$

Department of General, Visceral and Transplant Surgery,

University of Tuebingen,

Tuebingen, Germany

e-mail: w.v.petersen@gmx.de 